\title{
Screening and Bioinformatics Analysis of Proteins Interacting with StMAPKK1 in Potato by Yeast Two-Hybrid System
}

Liao Yuqiu ${ }^{1}$ Wang Fangfang ${ }^{1} \mathrm{Zhu} \mathrm{Xi}^{2}$ Zhang Ning ${ }^{1} \rrbracket$ Si Huaijun ${ }^{1,3}$

1 College of Life Science and Technology, Gansu Agricultural University, Lanzhou, 730070, China

2 College of Agronomy, Gansu Agricultural University, Lanzhou 730070, China

3 Gansu Provincial Key Laboratory of Aridland Crop Science, Lanzhou 730070, China

\ Corresponding author Email: ningzh@gsau.edu.cn

Molecular Plant Breeding, 2020, Vol.11, No.3 doi: 10.5376/mpb.2020.11.0003

Received: 04 Jun., 2020

Accepted: 06 Jun., 2020

Published: 19 Jun., 2020

Copyright (c) 2020 Liao et al., This article was first published in Molecular Plant Breeding in Chinese, and here was authorized to translate and publish the paper in English under the terms of Creative Commons Attribution License, which permits unrestricted use, distribution, and reproduction in any medium, provided the original work is properly cited.

Preferred citation for this article:

Liao Y.Q., Wang F.F., Zhu X., Zhang N., and Si H.J., 2020, Screening and bioinformatics analysis of proteins interacting with StMAPKK1 in potato by yeast Two-hybrid system, Molecular Plant Breeding, 11(3): 1-8 (doi: 10.5376/mpb.2020.11.0003)

\begin{abstract}
Mitogen-activated protein kinase (MAPK) cascade reaction is one of important and complex signal networks involved in plant growth and development, hormone and stress response. As one of its main members, mitogen-activated protein kinase kinase (MAPKK) is located in the middle of the cascade reaction and plays a key role in signal collection and divergence. There were shown that potato (Solanum tuberosum L.) StMAPKK1 (PGSC0003DMT400000744) gene responded to drought stress. Therefore, StMAPKK1 gene was firstly selected to screen its interacting protein. In this study, the bait vector pGBKT7-StMAPKK1 was constructed by homologous recombination and used to screen potato cDNA library by yeast (Saccharomyces cerevisiae) two-hybrid system. Five StMAPKK1-interacting proteins, hydrolase (hydrolyzing O-glycosyl compound), RING-H2 subgroup RHE protein, cyanate hydratase, ARF GTPase activator, and a C2 domain-containing protein, were obtained through this screening and were identificated by bioinformatics analysis, and the interaction was verified by small-scale hybridization verification. The results provided theoretical basis for further study on the signal pathway and biological function of potato StMAPKK1.
\end{abstract}

Keywords Potato; StMAPKK1; Yeast two-hybrid; Interacting protein

Mitogen-activated protein kinase (MAPK) cascade reaction is a kind of highly conserved biosignal transduction module in eukaryotes (MAPK Group, 2002). In plant, the MAPK signal pathway is almost involved in various growth and development processes and stress reaction of various plant biotic and abiotic stress, so that a large complex and cross-communication biological signal transduction network can be formed in the cell, the basic conditions for rapid distribution of information are provided for the growth and development in plant and stress of the external conditions in the process of it. A plurality of miscellaneous signal paths are connected, the upstream received stimulation signals are classified and transmitted to the downstream, and other functional genes which can cause physiological function changes in the plant can be started as needed.

There are three main numbers of MAPK cascade reaction, mitogen activated protein kinase kinase kinase (MAPKKK), mitogen activated protein kinase kinase (MAPKK) and mitogen activated protein kinase (MAPK). Phosphorylation at specific motifs acts on the upstream and downstream of certain members to form cascade signaling pathways (Iftikhar et al, 2017). The number of MAPKKs members is the least, and it can be divided into four subfamilies A, B, C, D. MAPKKs is a double kinase, it can be activated by upstream MAPKKKs phosphorylation and activate downsteam MAPKs through phosphorylation. MAPKK responsed to drought stress in plants, AtMAPKKK18-AtMKK3-AtMPK1/2 involved in drought resistance regulation with ABA induction dependence (Li et al., 2017). Overexpression of ZmMKK1 or ZmMKK4 in Arabidopsis enhanced drought resistance (Cai et al., 2014; Kong et al., 2011). GhMKK3 in cotton enhanced drought resistance through regulating stomatal size and root growth (Wang et al., 2016). Also, studies have found that OsMKK1 were involved in salt stress signaling in rice (Wang et al., 2014) and OsMKK6 played a role in low temperature and salt stress (Xie et al., 2012). 
$M A P K K$ s family genes in potato have been identified (Liu, 2017) and five MAPKK genes were obtained. They were named through tomato homology analysis StMAPKK1 (PGSC0003DMT400000744), StMAPKK2 (PGSC0003DMT400023739), StMAPKK3 (PGSC0003DMT400014637), StMAPKK4 (PGSC0003DMT400083995) and StMAPKK5 (PGSC0003DMT400039329). The quantitative results of potato StMAPKK genes under different treatments (including $4^{\circ} \mathrm{C}, 45^{\circ} \mathrm{C}, 20 \% \mathrm{PEG}, 200 \mathrm{mmol} / \mathrm{L} \mathrm{NaCl}, 10 \mathrm{mmol} / \mathrm{L} \mathrm{H}_{2} \mathrm{O}_{2}, 100 \mu \mathrm{mol} / \mathrm{L} \mathrm{MeJA}, 100 \mu \mathrm{mol} / \mathrm{L}$ $\mathrm{SA}, 100 \mu \mathrm{mol} / \mathrm{L} \mathrm{ABA}$ ) showed that the expression of StMAPKK1 genes increased significantly under drought stress. Therefore, the StMAPKK1 gene was selected as the experimental object, and the protein interacting with StMAPKK1 was screened by yeast two-hybrid technique, so as to explore the signal pathway of StMAPKK1 gene in potato under drought stress.

\section{Results}

\subsection{Construction of yeast two-hybrid bait vector pGBKT7-StMAPKK1}

The full length transcription sequence of StMAPKK1 gene (PGSC0003DMT400000744) is $1666 \mathrm{bp}$. The inserted fragment designed according to the design principle of homologous recombination primers would have homologous sequence $21 \mathrm{bp}$ at the end of insertion fragment $5^{\prime}$ and $3^{\prime}$ respectively, so the product size is about 1 $708 \mathrm{bp}$, which is consistent with the results of electrophoresis (Figure 1A). pGBKT7 plasmid size is $7303 \mathrm{bp}$. The linear plasmid was obtained from pGBKT7 plasmid digestion by Pst I and Nde I . The size of the linear plasmid is about $7270 \mathrm{bp}$, and the electrophoresis detection was in accordance with the expected size (Figure 1B).

The recombinant product was transformed into E.coli DH5 $\alpha$ competent cell and coated on LB solid plate (50 $\mathrm{mg} / \mathrm{L} \mathrm{Kan}$ ). Six single colonies were identified by PCR, and there were obvious bands at about 1708 bp (Figure 1C). StMAPKK1 gene had enzyme cutting sites of Nde I at $572 \mathrm{bp}$ and $582 \mathrm{bp}$, so the recombinant plasmid pGBKT7-StMAPKK1 digestion by Pst I and Nde I should have three fragments about $7270 \mathrm{bp}, 1126 \mathrm{bp}$ and $572 \mathrm{bp}$, respectively. The results of electrophoresis (Figure 1D) were in good agreement with the expected results. Mainwhile, the results of sequencing showed that StMAPKK1 gene had been successfully inserted into pGBKT7 vector (Figure 2).
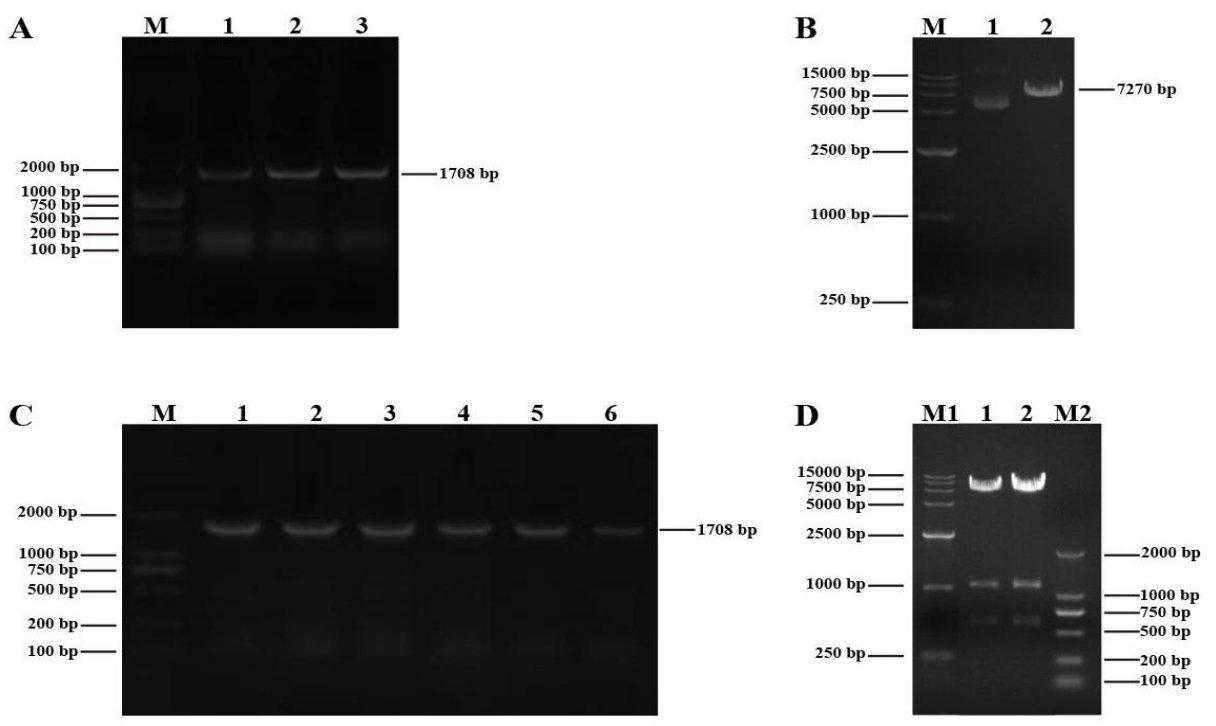

Figure 1 Construction of yeast two-hybrid bait vector pGBKT7-StMAPKK1

Note: A: Amplification of StMAPKK1 gene M: Trans2K DNA molecular marker, 1-3: PCR product of StMAPKK1 gene; B: The double enzyme digestion linearization of pGBKT7 plasmid M: DL15000 DNA molecular marker, 1: pGBKT7 vector plasmid, 2: Pst I and Nde I restriction endonuclease digestion to obtain the linear vector of pGBKT7; C: Identification of recombinant plasmid pBGKT7-StMAPKK1 by PCR M: Trans2K DNA molecular marker, 1-6: PCR product of single colony solution; D: Identification of the recombinant plasmid pGBKT7-StMAPKK1 digestion by Nde I and Pst I M1: DL15000 DNA molecular markers, 1 and 2: Products of pGBKT7-StMAPKK1 digestion by Nde I and Pst I , M2: Trans2K DNA molecular markers 
Molecular Plant Breeding 2020, Vol.11, No.3, 1-8

http://genbreedpublisher.com/index.php/mpb

StMa $2 \mathrm{KK} 1$

Consengrs

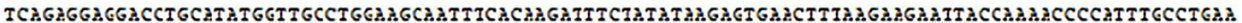
getgectggazgcaztecacagatetctatatagagegazettaagagazteaccazaccceategectgaz

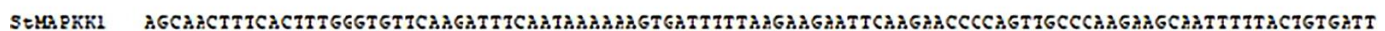

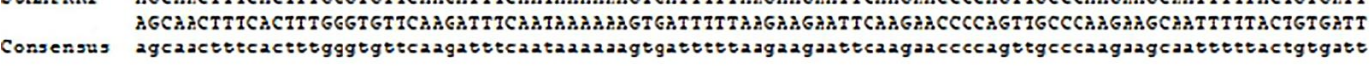

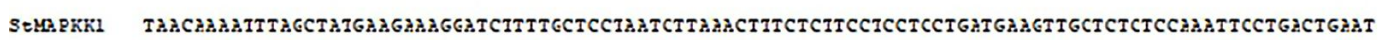
TAACAAATTTAGCTATGAGAAGGACTTTTGCTCCTAATCTTAAACTITCTCTTCCTCCTCCTGATGAGTTGCTCTCTCCAAATTCTGACTGAT

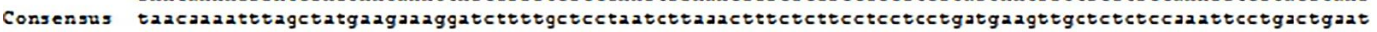

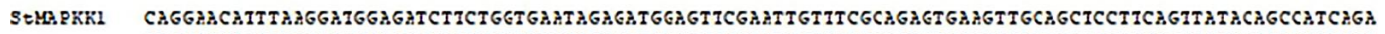

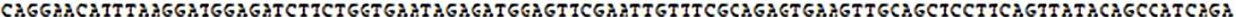

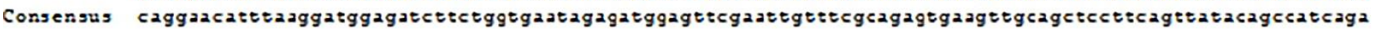

SEMARK1 CAACCAGTIATGCTTAGCTGATTTTGAGCAGTIAAGITATIGGAAGGGAATGGTGGTATIGTGCGGCTGGTTCAGCATAATGGACAGGGCATTT CAACCAGTIATGCTTAGCTGATTTIGAAGCAGTTAMATTATIGGAMGGGAATGGTGGTATIGTGCGGCTGGTTCAGCATAAMTGACAGGGCAATTT

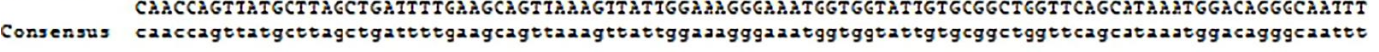

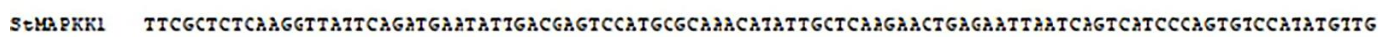
TTCGCTCTCAAGTTATTCAGATGATAT1GACGATCCATGCGCAACATATTGCTCAAGACTGAGATTATCAGTCATCCCAGTGTCCATATGTTG

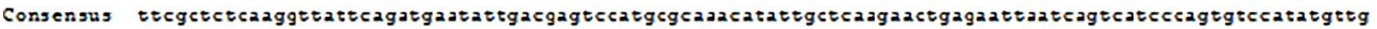

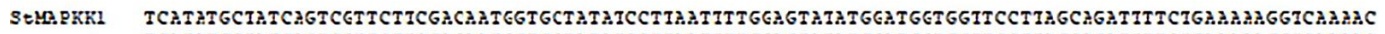

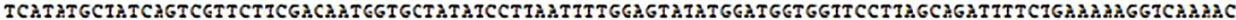

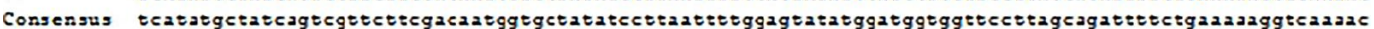

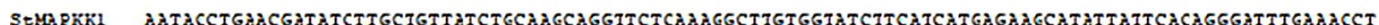
AaTACCI

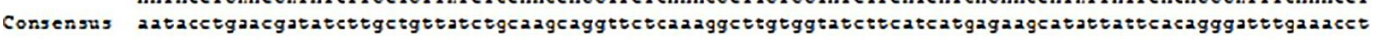

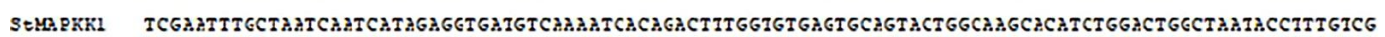

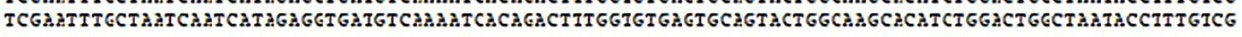

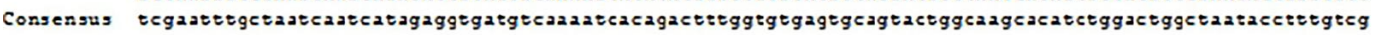

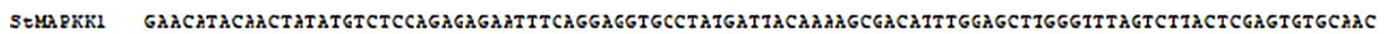
GAACATACACTATATGTCTCCAGAGAGATTTCAGGAGGTGCCTATGAT7ACAAAAGCGACATTTGGAGCTIGGGTTTAGTCTIACTCGAGTGTGCAAC

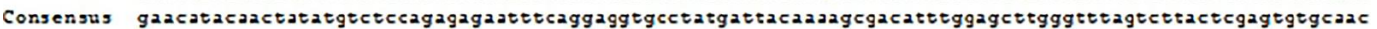

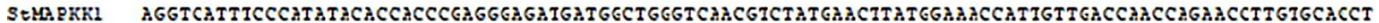
aGGTCaTTTCCCaTaTaCaCcaccCGaGGGa

Consengus aggtcattcccatatacaccacccgagggagatgatggctgggtcazegtctatgazcteatggazaccattgttgaccazccagazcctegtgcacct

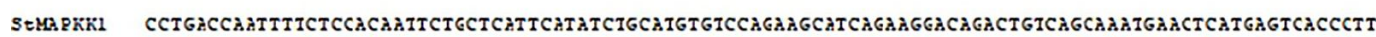

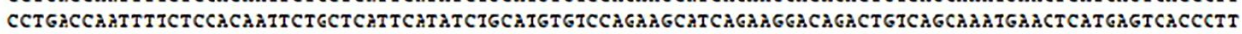

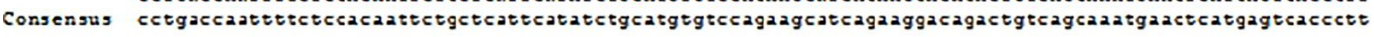

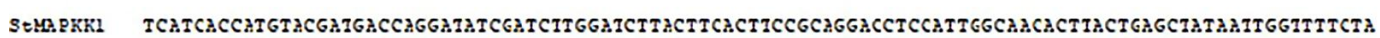

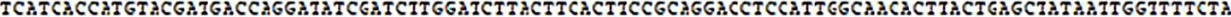

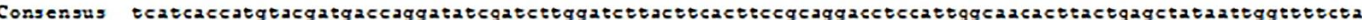

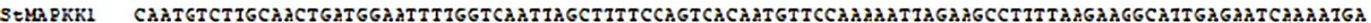
cגarGTCTIGCגacTG

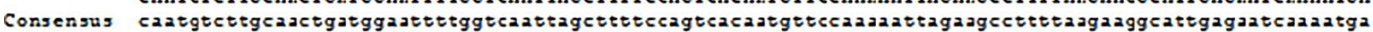

SEMAPKK1 AGCAGATGGAGCCATTGTTGTACTTTTCAaGCCTCCGGTAGGTAGCGTTGGGAGTGTAACTGTGACATTTTCTACTATGTATGTGATTCAAATGGAACA

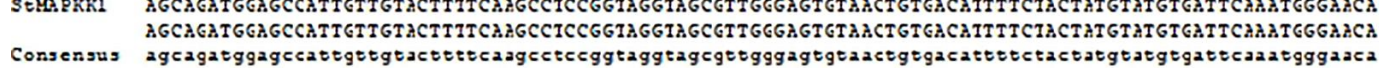

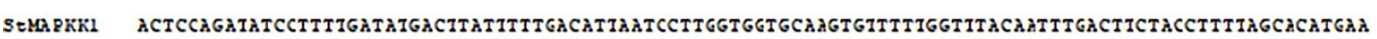
ACTCCAGATATCCTTI7GATATGACITATITITGACATIAATCCITGGTGGTGCAAGTGITITIGGTITACAATITGACTICTACCTITIAGCACATGAA

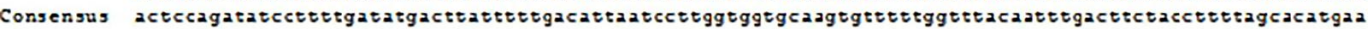

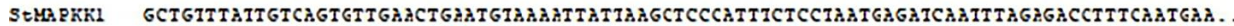

GCTGITT ITGTCAGTETTG A

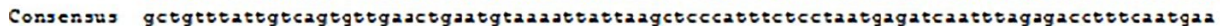

StMA.PKK1

Consensus

aтаaстассат)

Figure 2 Sequencing result of pGBKT7-StMAPKK1

\subsection{Detection of toxicity and self-activating activity of yeast two-hybrid bait vector}

Y187 yeast containing pGBKT7 empty vector or pGBKT7-StMAPKK1 bait vector was coated on single deficient medium SD/-Trp/X- $\alpha$-gal. The growth number of the two strains was about the same (Figure 3), which indicated that the bait vector has no toxic to yeast cells. At the same time, the two strains did not grow on SD/-Trp/-His/ $\mathrm{X}$ - $\alpha$-gal or $\mathrm{SD} /-\mathrm{Trp} /$-Ade/X- $\alpha$-gal, indicating that the strain had no self-activating activity and could not activate downstream reporter genes alone.

\subsection{Small-scale hybridization verification of positive clone}

The hybrid solution of bait protein and library was coated on 50 quadruple dropout media QDO. A total of 406 single colonies with large diameter were selected for identification and screening by X- $\alpha$-Gal staining. 210 
colonies which grew within 48 hours and displayed as blue were regarded as positive clones. The positive rate was $51.72 \%$. Five different StMAPKK1 interacting proteins named $\mathrm{C} 1$ to $\mathrm{C} 5$, respectively, were identified by electrophoresis and sequencing. The proportion was $87 \%, 2.9 \%, 4.8 \%, 2.9 \%$ and $2.9 \%$, respectively.

Five StMAPKK1 interacting protein gene plasmids were randomly selected and transferred back into AH109 yeast. The AH109 with plasmid was crossbred with Y187 containing bait vector and coated on QDO/X- $\alpha-G a l$ medium to culture. After two days of culture, the colonies with different blue depths grew at all five points (Figure 4). The results showed that all the five positive cloned genes could be verified by small-scale cross rotation, and the interaction between them was true and credible.

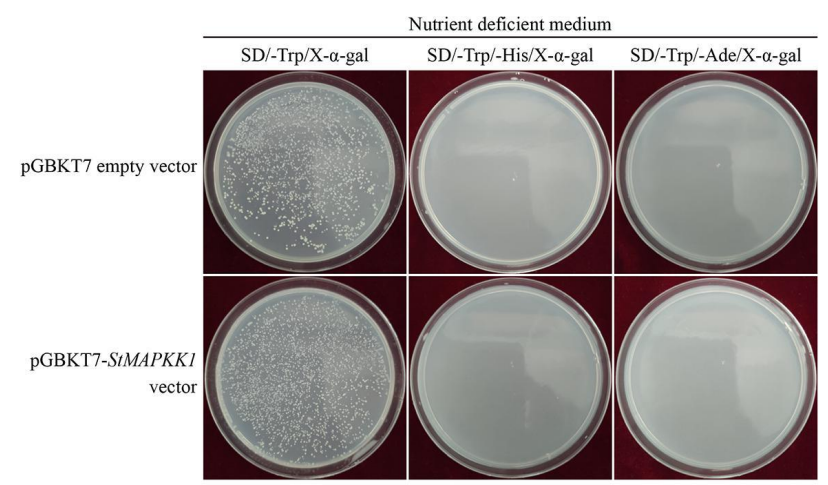

Figure 3 Detection of toxicity and self-activating activity of yeast two-hybrid bait vector pGBKT7-StMAPKK1

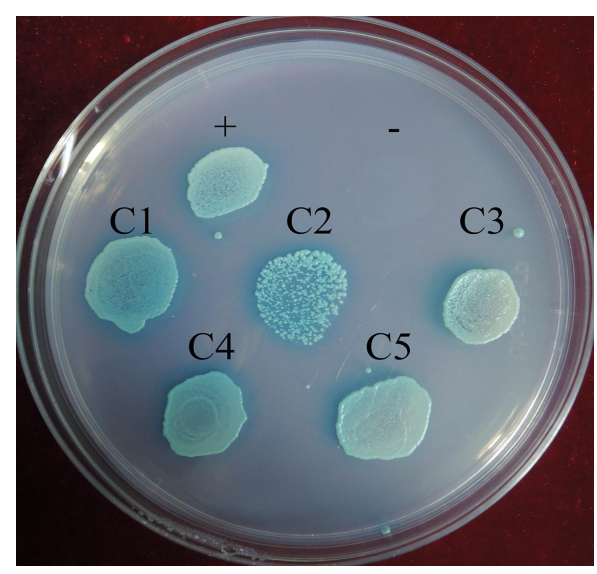

Figure 4 Small-scale hybridization verification of positive clones

Note: +: Positive control AH109 (pGADT7-RecT)×Y187 (pGBKT7-53); -: Negative control AH109 (pGADT7-RecT) ×Y187 (pGBKT7-Lam); C1 C5: Numbers of positive clones

\subsection{Identification of positive clones}

By sequencing and analysis of interacting protein genes, five StMAPKK1 interacting proteins C1-C5 were obtained, and then the basic physical and chemical properties of these genes were obtained (Table 1). The names of these five genes from NCBI were hydrolase, (hydrolyzing O-glycosyl compounds), RING-H2 subgroup RHE protein, cyanate hydratase, ARF GTPase activator and $\mathrm{C} 2$ domain-containing protein.

\section{Discussion}

After sequencing the positive clones, A total of five StMAPKK1 interacting proteins were obtained: Hydrolase (hydrolyzing O-glycosyl compounds), RING-H2 subgroup RHE protein, cyanate hydratase, ARF GTPase activator and $\mathrm{C} 2$ domain-containing protein. 
Molecular Plant Breeding 2020, Vol.11, No.3, 1-8

$\mathrm{http} / / /$ genbreedpublisher.com/index.php/mpb

Table 1 Details information of proteins interacting with StMAPKK1

\begin{tabular}{|c|c|c|c|c|c|c|}
\hline Clone & Gene ID & PGSC ID & Annotation of gene name & $\begin{array}{l}\text { Full length } \\
\text { of gene (bp) }\end{array}$ & $\begin{array}{l}\text { Protein } \\
\text { length }(\mathrm{aa})\end{array}$ & Chromosomal location \\
\hline $\mathrm{C} 1$ & 102586320 & PGSC0003DMG400030891 & $\begin{array}{l}\text { Hydrolase, hydrolyzing } \\
\text { O-glycosyl compounds }\end{array}$ & 4178 & 864 & $\begin{array}{l}\text { chr07:4096440 } \\
. .4101254\end{array}$ \\
\hline $\mathrm{C} 2$ & 102591415 & PGSC0003DMG400011326 & $\begin{array}{l}\text { RING-H2 subgroup RHE } \\
\text { protein }\end{array}$ & 921 & 306 & chr01:57283292..57284878 \\
\hline $\mathrm{C} 3$ & 102578903 & PGSC0003DMG400017160 & Cyanate hydratase & 3550 & 162 & chr09:56757059..56761063 \\
\hline $\mathrm{C} 4$ & 102593804 & PGSC0003DMG400007759 & ARF GTPase activator & 2253 & 164 & chr00:33717961..33720534 \\
\hline $\mathrm{C} 5$ & 102585714 & PGSC0003DMG400023218 & $\begin{array}{l}\text { C2 domain-containing } \\
\text { protein }\end{array}$ & 3074 & 167 & chr00:22575898..22579255 \\
\hline
\end{tabular}

Among them, the interacting protein $\mathrm{C} 1$ is hydrolase (hydrolyzing O-glycosyl compounds), and it can be also noted as galactitol-sucrose galactosyltransferase. It belongs to the GH36C subfamily of 11 subfamilies (GH36A to GH36K) in the glycoside hydrolase family 36 . The members of the family can also be called raffinose synthase (RS) or seed imbibition protein I (Sip I). Raffinose synthase (EC 2.4.1.82) is the key enzyme that channels sucrose into the raffinose oligosaccharide pathway, it plays an important role in gaining drought resistance and prolonging the life of plant seeds (Peterbauer et al., 2002). In germinating maize seeds, some studies have shown that raffinose synthases are exclusively responsible for raffinose family oligosaccharides (RFO) breakdown (Andreas et al., 2008). CsRS expression was induced by low temperature and exogenous plant hormone abscisic acid (ABA) in cucumber leaves and fruits, RS activity and the content of raffinose increased gradually (Sui et al., 2012). Also in beet (Beta vulgaris L.), two kinds of raffinose synthase identified in the study were proved to be involved in cold stress and salt stress responses (Kito et al., 2018). The interacting protein C2 was RING-H2 subgroup RHE protein, it is a cyclic $\mathrm{H} 2$ protein with E3 ubiquitin ligase activity and belongs to ATL (Arabidopsis toxicos para levadura) gene family (MartínezGarcía et al., 1996). It was proved that PtaRHE1 was involved in the development of secondary phloem fibers in poplar hybrid varieties (Baldacci-Cresp et al., 2015). There are also some studies shown that the $A T L$ gene family may be involved in early defense responses to pathogen attack (Salinas-Mondragón et al., 1999). The interacting protein C3 cyanate hydratase also known as cyanoate lyase (EC:4.2.1.104), is responsible for the hydrolysis of cyanate ester and exists in bacteria and plants, so that the organism with this kind of enzyme can overcome the toxicity of environmental cyanate ester (Sung and Fuchs, 1988). The interacting protein C4 ARF (ADP-ribosylation factor) GTPase activating factor is often involved in vesicle transport, especially in coatomer-coated vesicle transport between Golgi cisternae (Rothman and Wieland, 1996). In domain analysis, this activating factor contains $C 2$ domain, which is involved in regulating membrane transport (Thomas and Rizo, 1996). At the same time, the interacting protein C5, a C2 domain-containing protein, the $\mathrm{C} 2$ domain could exhibit a distinct characteristic of binding to a variety of different ligands and substrates, including $\mathrm{Ca}^{2+}$, phospholipids, phosphoinositides, and intracellular proteins (Cho and Stahelin, 2006). A protein, OsPBP1, containing C2 domain in rice has been shown to regulate pollen fertility through $\mathrm{Ca}^{2+}$ and phospholipid signaling pathways (Yang et al., 2008).

In this experiment, the StMAPKK1 interacting proteins screened by yeast two-hybrid technique were different from the expected target results, other types of kinases in the MAPKs cascade reaction, such as MAPKKKs and MAPKs, were not obtained. There were some studies showed that there are other cascade pathways in addition to the typical MAPK pathway MAPKKK-MAPKK-MAPK, which may be cross-transmitted with other signal pathways. 


\section{Materials and Methods}

\subsection{Material for experiment}

The yeast two-hybrid cDNA library of the potato tetraploid cultivar 'Zihuabai' (Liang, 2017), yeast (Saccharomycescerevisiae) strain Y187 and AH109, Esche-richia coli strain and bait vector pGBKT7 were all preserved the laboratory of the college of life science and technology, Gansu agricultural university.

\subsection{Construction of yeast two-hybrid bait vector pGBKT7-StMAPKK1}

Pst I and Nde I restriction endonuclease were used to linearize the carrier pGBKT7 and perform gel recovery. PCR response amplification of potato StMAPKK1 gene target fragment reaction system were $2 \times$ Power Taq PCR Master MIX $10 \mu \mathrm{L}$, Potato 'Atlantic' leaf cDNA template $1 \mu \mathrm{L}, 10 \mu \mathrm{mol} / \mathrm{L}$ StMAPKK1-F (5'-TCAGAGGAGGAC CTGCATATGGTTGCCTGGAAGCAATTTCACA-3'), StMAPKK1-R (5'-CTAGTTATGCGGCCGCTGCAGTT CATTGAAAGGTCTCTAAATTGATCTC-3') each $1 \mu \mathrm{L}$ (The underlined part is homologous sequences of vector), $\mathrm{ddH}_{2} \mathrm{O} 7 \mu \mathrm{L}$. The amplification conditions to get target fragment of StMAPKK1 gene by PCR were as follows: $94^{\circ} \mathrm{C}$ for $5 \mathrm{~min}$, followed by 35 cycles of $94^{\circ} \mathrm{C}$ for $30 \mathrm{~s}, 62^{\circ} \mathrm{C}$ for $30 \mathrm{~s}, 72^{\circ} \mathrm{C}$ for $67 \mathrm{sec}$, and a final extension at $72^{\circ} \mathrm{C}$ for $10 \mathrm{~min}$. Then the PCR products were also purified by agarose gel recovery, and the fragment size was $1708 \mathrm{bp}$. The recovered linear vector and PCR product of StMAPKK1 gene were calculated according to the ClonExpress ${ }^{\circledR}$ II One Step Cloning Kit specification from Vazyme company to establish the homologous recombination reaction system, and the reaction program was $37^{\circ} \mathrm{C} 30 \mathrm{~min}$ and stored at $4{ }^{\circ} \mathrm{C}$. The recombinant product was transformed into $E$. coli $\mathrm{DH} 5 \alpha$ by heat shock method and the bacteria liquid was coated with LB medium $(50 \mathrm{mg} / \mathrm{L} \mathrm{Kan})$ for overnight culture at $37^{\circ} \mathrm{C}$. A single colony was selected for PCR detection and sequencing.

\subsection{Detection of toxicity and self-activating activity of yeast two-hybrid bait vector}

The pGBKT7-StMAPKK1 bait vector plasmid and the pGBKT7 empty vector plasmid were transformed into the yeast Y187 by the polyethylene glycol/ lithium acetate method, respectively. The transformation products were respectively coated with $\mathrm{SD} /-\operatorname{Trp}$ plates and incubated at $30^{\circ} \mathrm{C}$ for $1-2$ days. Choose the pGBKT7-StMAPKK1 bait vector and the pGBKT7 empty vector single colony with the size of 2-3 $\mathrm{mm}$ and growing at $30^{\circ} \mathrm{C}$ for 2 days. Single colony uniformly was mixed into $500 \mu \mathrm{L} \mathrm{SD/-Trp} \mathrm{liquid} \mathrm{culture} \mathrm{medium,} \mathrm{and} \mathrm{coated} 80 \mu \mathrm{L}$ on nutrient deficient mediums SD/-Trp/X- $\alpha$-Gal, SD/-His/-Trp/X- $\alpha$-Gal and SD/-Ade/-Trp/X- $\alpha$-Gal. The coated plates were incubated at $30^{\circ} \mathrm{C}$ for 5 to 7 days. The remaining bacterial liquid was stored at $4{ }^{\circ} \mathrm{C}$. According to the growth condition of the colony, we can figure whether the bait vector has toxic or self-activating activity.

\subsection{Hybridization between bait protein and yeast library}

The single colony of bait vector was picked into $50 \mathrm{~mL} \mathrm{SDO} /-\operatorname{Trp} / \mathrm{Kan}(20 \mu \mathrm{g} / \mathrm{mL})$ medium, cultured overnight $(16 \sim 24 \mathrm{~h})$ at $30^{\circ} \mathrm{C}$ for $230 \mathrm{rpm} / \mathrm{min}$, and then centrifuge to get sediment and resuspend it with $5 \mathrm{~mL} \mathrm{SDO/-Trp}$ liquid medium. Y187 bacteria with the bait vector solution $5 \mathrm{~mL}$ and library AH109 bacteria solution $1 \mathrm{~mL}$ were used in $2 \mathrm{~L}$ triangular flask. Then add $50 \mathrm{~mL} 2 \times$ YPDA/Kan $(50 \mu \mathrm{g} / \mathrm{mL}), 30^{\circ} \mathrm{C}$ incubated in shaking table at low speed (30 50 rpm/min) for 20 to $24 \mathrm{~h}$. The $5000 \mathrm{rpm}$ centrifugation of the hybrid solution for $10 \mathrm{~min}$ and the precipitation was resuspended with $10 \mathrm{~mL} 0.5 \times$ YPDA $/$ Kan $(50 \mu \mathrm{g} / \mathrm{mL})$. The resuspending was coated on 50 quadruple dropout media QDO (SD/-Ade/-His/-Leu/-Trp), each plate was $100 \mu \mathrm{L}$, cultured at $30^{\circ} \mathrm{C}$ for 7 days, the high rigorous interaction screening was carried out. The single colony point with larger diameter $(>2 \mathrm{~mm})$ was selected to QDO medium coated with $100 \mu \mathrm{L} \mathrm{X- \alpha -Gal} \mathrm{for} \mathrm{preliminary} \mathrm{identification.} \mathrm{On} \mathrm{the} \mathrm{selection} \mathrm{medium}$ QDO/X- $\alpha-G a l$, the substrate $\mathrm{X}-\alpha-\mathrm{Gal}$ can be hydrolyzed and a distinct blue color is presented as a positive clone. The positive clones were identified by PCR, the primers (5'-3') were pGADT7-F TAATACGACTCACTATAGG GCGAGCG and pGADT7-R GTGAACTTGCGGGGTTTTTCAGTAT, which were designed according to sequences at both ends of restriction enzyme sites of the pGADT7 vector. The obtained PCR product is subjected to electrophoresis detection and sent to Suzhou Jinwei Biotechnology Co., Ltd. for sequencing.

\subsection{Small-scale hybridization verification of positive clones}

According to $\mathrm{Xu}$ et al. (2003), positive single clone yeast plasmids were extracted. The positive plasmid containing correct ORF was transformed into yeast AH109 receptive cells and then hybridized with yeast Y187 
containing bait vector. AH109 (pGADT7-RecT) ×Y187 (pGBKT7-53) and AH109 (pGADT7-RecT) ×Y187 (pGBKT7-Lam) were used as positive and negative controls, respectively. $25 \mu \mathrm{L}$ of the above hybrid solution was dripped on the fresh QDO/X- $\alpha-\mathrm{Gal}$ plate. The round plaque was cultured in dark at $30^{\circ} \mathrm{C}$. The growth and discoloration were observed to verify the authenticity of the interaction.

\subsection{Bioinformatics analysis and identification of positive cloned genes}

The sequencing results of interacting protein were identified by Blast comparison analysis in potato database of NCBI (https://www.ncbi.nlm.nih.gov/), PGSC (http://solanaceae.plantbiology.msu.edu/pgsc download.shtml) and Phytozome v12.1 (https://phytozome.jgi.doe.gov/pz/portal.htm), the protein name, chromosome position, fulllength gene and protein sequences of interacting proteins of StMAPKK1 can be obtained.

\section{Authors' contributions}

Liao Yuqiu is the experimental designer of this research and the executor of the experimental research, carries on the data collation and the writing of the first draft of the paper; Wang Fangfang and Zhu Xi participate in part of the experiment; Zhang Ning and Si Huaijun are the project leaders to guide the experimental design, data statistics, paper writing and revision. All authors read and approved the final manuscript.

\section{Acknowledgments}

This study was co-funded by the National Natural Science Foundation of China (No.31960444) and the Open Foundation Project (No.GSCS-2019-Z03) of the Key Laboratory of Arid Habitat Cropology, Gansu Agricultural University.

\section{References}

Andreas B., Peterbauer T., Hofmann J., and Richter A., 2008, Enzymatic breakdown of raffinose oligosaccharides in pea seeds, Planta, 228(1): 99-110 https://doi.org/10.1007/s00425-008-0722-4 PMid: 18335235

Baldacci-Cresp F., Moussawi J., Leplé J., Van A.R., Kohler A., Candiracci J., Twyffels L., Spokevicius A., Bossinger G., Laurans F., Brunel N., Vermeersch M., Boerjan W., Jaziri M. E., and Baucher M., 2015, PtaRHE1, a Populus tremula×Populus alba RING-H2 protein of the ATL family, has a regulatory role in secondary phloem fibre development, Plant Journal for Cell \& Molecular Biology, 82(6): 978-990

https://doi.org/10.1111/tpj.12867

PMid:25912812

Cai G., Wang G., Wang L., Liu Y., Pan J., and Li D., 2014, A maize mitogen-activated protein kinase kinase, ZmMKK1, positively regulated the salt and drought tolerance in transgenic Arabidopsis, Journal of Plant Physiology, 171(12): 1003-1016

https://doi.org/10.1016/j.jplph.2014.02.012

PMid:24974327

Cho W., and Stahelin R.V., 2006, Membrane binding and subcellular targeting of C2 domains, Biochimica et Biophysica Acta, 1761(8): 838-849 https://doi.org/10.1016/j.bbalip.2006.06.014 PMid: 16945584

Iftikhar H., Naveed N., Virk N., Bhatti M.F., and Song F., 2017, In silico analysis reveals widespread presence of three gene families, MAPK, MAPKK and MAPKKK, of the MAPK cascade from crop plants of Solanaceae in comparison to the distantly-related syntenic species from Rubiaceae, coffee, Peer J., 5: e3255

https://doi.org/10.7717/peerj.3255

PMid:28603666 PMCid:PMC5463992

Kito K., Yamane K., Yamamori T., Matsuhira H., Tanaka Y., and Takabe T., 2018, Isolation, functional characterization and stress responses of raffinose synthase genes in sugar beet, J Plant Biochem. Biot., 27(1): 36-45

https://doi.org/10.1007/s13562-017-0413-y

Kong X.P., Pan J.W., Zhang M.Y., Xing X., Li D., Zhou Y., Liu Y., Li D.P., and Li D.Q., 2011, ZmMKK4, a novel group C mitogen-activated protein kinase kinase in maize (Zea mays), confers salt and cold tolerance in transgenic Arabidopsis, Plant Cell Environ., 34(8): 1291-1303 https://doi.org/10.1111/j.1365-3040.2011.02329.x PMid:21477122

Li Y.Y., Cai H.X., Liu P., Wang C.Y., Gao H.Y., Wu C.A., Yan K., Zhang S.Z., Huang J.G., and Zheng C.C., 2017, Arabidopsis MAPKKK18 positively regulates drought stress resistance via downstream MAPKK3, Biochem. Bioph. Res. Co., 484(2): 292-297

https://doi.org/10.1016/j.bbrc.2017.01.104

PMid:28131829

Liang L.N. 2017. Yeast cDNA library construction and ERF transcription factor screening of potato (Solanum tuberosum L.) under drought stress. Thesis for M S., College of Life Science and Technology, Gansu Agricultural University, Supervisor: Zhang N. pp. 21-30 
Liu X., 2017, Identification of mitogen activated protein kinases kinases genes and screening of drought-related functional genes in potato, Thesis for M.S., College of Life Science and Technology, Gansu Agricultural University, Supervisor: Si H.J., pp.37-40

MAPK Group, 2002, Mitogen-activated protein kinase cascades in plants: a new nomenclature, Trend Plant Sci., 7(7): 301-308

MartínezGarcía M., GarcidueñasPiña C., Guzmán P., MartinezGarcia M., GarciduenasPina C., and Guzman P., 1996, Gene isolation in Arabidopsis thaliana by conditional overexpression of cDNAs toxic to saccharomyces cerevisiae: identification of a novel early response zinc-finger gene, Molecular \& General Genetics Mgg., 252(5): 587-596

https://doi.org/10.1007/BF02172405

PMid:8914520

Peterbauer T., Mach L., Mucha J., and Richter A., 2002, Functional expression of a cDNA encoding pea (Pisum sativum L.) raffinose synthase, partial purification of the enzyme from maturing seeds, and steady-state kinetic analysis of raffinose synthesis, Planta, 215(5): 839-846 https://doi.org/10.1007/s00425-002-0804-7

PMid: 12244450

Rothman J.E., and Wieland F.T., 1996, Protein sorting by transport vesicles, Science, 272(5259): 227-234 https://doi.org/10.1126/science.272.5259.227 PMid: 8602507

Salinas-Mondragón R.E., Garcidueñas-Piña C., and Guzmán P., 1999, Early elicitor induction in members of a novel multigene family coding for highly related RING-H2 proteins in Arabidopsis thaliana, Plant Mol. Biol., 40(4): 579-90

https://doi.org/10.1023/A:1006267201855

PMid:10480382

Shi B., Ni L., Liu Y., Zhang A., Tan M., and Jiang M., 2014, OsDMI3-mediated activation of OsMPK1 regulates the activities of antioxidant enzymes in abscisic acid signalling in rice, Plant, Cell \& Environment, 37(2): 341-352

https://doi.org/10.1111/pce.12154

PMid:23777258

Sui X.L., Meng F.Z., Wang H.Y., Wei Y.X., Li R.F., Wang Z.Y., Hu L.P., Wang S.H., and Zhang Z.X., 2012, Molecular cloning, characteristics and low temperature response of raffinose synthase gene in Cucumis sativus L, J Plant Physiol., 169(18): 1883-1891

https://doi.org/10.1016/i.jplph.2012.07.019

PMid:22985990

Sung Y.C., and Fuchs J.A., 1988, Characterization of the Cyn operon in Escherichia coli K12, J Biol. Chem., 263(29): 14769-14775

Thomas C.S., and Rizo J., 1996, Synaptotagmins: C2-domain proteins that regulate membrane traffic, Neuron, 17(3): 379-388 https://doi.org/10.1016/S0896-6273(00)80171-3

Wang C., Lu W.J, He X.W., Wang F., Zhou Y.L., Guo X.L., and Guo X.Q., 2016, The cotton mitogen-activated protein kinase kinase 3 functions in drought tolerance by regulating stomatal responses and root growth, Plant Cell Physiol., 57(8): 1629-1642

https://doi.org/10.1093/pcp/pcw090

PMid:27335349

Wang F.Z., Jing W., and Zhang W.H., 2014, The mitogen-activated protein kinase cascade MKK1-MPK4 mediates salt signaling in rice, Plant Sci., 227: 181-189

https://doi.org/10.1016/j.plantsci.2014.08.007

PMid:25219319

Xie G.S., Kato H., and Imai R., 2012, Biochemical identification of the OsMKK6-OsMPK3 signalling pathway for chilling stress tolerance in rice, Biochem. J., 443(1): 95-102

https://doi.org/10.1042/BJ20111792

PMid:22248149

Xie K.B., Chen J.P., Wang Q., Yang Y., 2014, Direct phosphorylation and activation of a mitogen-activated protein kinase by a calcium-dependent protein kinase in rice, Plant Cell, 26(7): 3077-3089

https://doi.org/10.1105/tpc.114.126441

PMid:25035404 PMCid:PMC4145133

Xu W.L., Liao Z.Y., Wang C.L., Yu L.H., Wang X.X., Yi S.Y., Zhang C.G., Qian L.J., 2003, The improvement of some methods involved in yeast two-hybrid experiments, Shengwu Jishu Tongbao (Letters in Biotechnology), 14(5): 372-374

Yang W.Q., Lai Y., Li M.N., Xu W.Y., and Xue Y.B., 2008, A novel C2-domain phospholipid-binding protein, OsPBP1, is required for pollen fertility in rice, Mol. Plant, 1(5): 770-785

https://doi.org/10.1093/mp/ssn035

PMid:19825580 